\title{
Incidence of Number of Roots in Maxillary Second Molars - A Cbct Analysis
}

\author{
Alagu Rathi Bharathi' and Anjaneyulu K² \\ ${ }^{1}$ Saveetha Dental College, Saveetha Institute of Medical and Technical \\ Sciences, Saveetha University, Chennai - 600077, India \\ ${ }^{2}$ Reader, Department of Conservative Dentistry and Endodontics,,Saveetha Dental College, Saveetha \\ Institute of Medical and Technical Sciences, Saveetha University, Chennai - 600077, India
}

\section{ABSTRACT}

The aim of the study is to find the incidence of the number of roots in maxillary second molars. In endodontic therapy, a comprehensive awareness of the root-canal anatomy is of great importance, and clinicians' failure to recognize an unusual canal morphology may lead to unsuccessful treatment. It is generally accepted that a serious explanation for the failure of passage therapy is an inability to localize and treat all of the canals of the basis canal system. In the present study, a total of 50 CBCT scan reports were collected from the Radiology department, Saveetha Dental College, Chennai, for evaluation. The CBCT scans were analysed for the number of roots and number of root canals present in maxillary second molars. The collected results were entered in Microsoft excel. Data analysis was done using SPSS software 20.0. The study results that the incidence of three roots are $83 \%$, two roots are $10 \%$, one root is $5 \%$ and four roots are 2 $\%$. The incidence of three root canals is $86 \%$, four root canals are $11 \%$ and two root canals are $3 \%$. Although the occurrence of maxillary second molar with one root or two roots isn't high, diagnosing these unusual cases at its early treatment stage is of significance for the success of endodontic treatment

KEY WORDS: MAXILLARY SECOND MOLARS, ROOT CANAL MORPHOLOGY, NUMBER OF ROOTS, NUMBER OF ROOT CANALS.

\section{INTRODUCTION}

Endodontic therapy consists of a series of treatments, including removing pulpal tissue, filing and shaping root canals, obturation of the root canal space, and placement of a permanent restoration for the tooth. In endodontic therapy, a comprehensive awareness of the root-canal anatomy is of great importance, and clinicians' failure

\section{ARTICLE INFORMATION}

*Corresponding Author: Kanjaneyulu.sdc@saveetha.com Received 14th June 2020 Accepted after revision 7th August 2020 Print ISSN: 0974-6455 Online ISSN: 2321-4007 CODEN: BBRCBA

Thomson Reuters ISI Web of Science Clarivate Analytics USA and Crossref Indexed Journal

\section{Clarivate
Analytics}

NAAS Journal Score 2020 (4.31) SJIF: 2020 (7.728)

A Society of Science and Nature Publication,

Bhopal India 2020. All rights reserved.

Online Contents Available at: http//www.bbrc.in/

Doi: http://dx.doi.org/10.21786/bbrc/13.7/70 to recognize an unusual canal morphology may lead to unsuccessful treatment (Sha, Sun and Chen, 2018). It is generally accepted that a serious explanation for the failure of passage therapy is an inability to localize and treat all of the canals of the basis canal system. The risk of missing anatomy during passage treatment is high due to the complexity of the basis canal system.

All categories of teeth may have extra roots and/or canals, but the likelihood of finding aberrant canal configurations is higher in premolars and molars. The impact of missed anatomy on the result of endodontic treatment is difficult to assess, and therefore the literature on this subject is limited; a promising approach for future investigation may be a comparison of the amount of canals found in failed treatment cases and after re-treatment. The clinical impact of missed anatomy is often clearly demonstrated with an outsized number of re-treatment case reports 
available within the literature; within the majority of those cases, failure of endodontic therapy is related to untreated canal space. Localization and treatment of this missed anatomy typically results in complete clinical and radiographic healing. (Cantatore, Berutti and Castellucci, 2006). The standard configuration of maxillary second molars has been described to have three roots and either three or four canals, with the fourth canal usually being the second mesiobuccal (MB2).

Peikoff et al. (Peikoff, Christie and Fogel, 1996) conducted a retrospective study of 520 endodontically treated maxillary second molars and have classified the anatomical root and canal variations found in maxillary second molar into six variants:

- Three separate roots (MB, DB, and P-palatal) with one canal in each root;

- Three separate roots (MB, DB, and P) and four canals (two in the MB root);

- Three roots but MB and DB canals combine to form a common buccal (B) with a separate P canal;

- One B and one P canal with a single canal in each;

- Single canal in a single conical root; and

- four separate roots - MB and DB and two palatal roots - a mesiopalatal and a disto palatal root.

Most of the researchers have focused on more number of roots (Deveaux, 1999) (Libfeld and Rotstein, 1989) (Fahid and Taintor, 1988), (Kottoor et al., 2010) and root canals in the maxillary second molar. Presence of single root and single canal is commonly found in mandibular second molar, describing the possibility of single root and single canal in maxillary second molar. Researchers have found only $0 \%-3.1 \%$ incidence of occurrence of single root and single canal in maxillary second molar. (Peikoff, Christie and Fogel, 1996)

We have numerous highly cited publications on well designed clinical trials and lab studies (Govindaraju, Neelakantan and Gutmann, 2017; Azeem and Sureshbabu, 2018; Jenarthanan and Subbarao, 2018; Manohar and Sharma, 2018; Nandakumar and Nasim, 2018; Teja, Ramesh and Priya, 2018; Janani and Sandhya, 2019; Khandelwal and Palanivelu, 2019; Malli Sureshbabu et al., 2019; Poorni, Srinivasan and Nivedhitha, 2019; Rajakeerthi and Ms, 2019; Rajendran et al., 2019; Ramarao and Sathyanarayanan, 2019; Siddique and Nivedhitha, 2019; Siddique et al., 2019; Siddique, Nivedhitha and Jacob, 2019). This has provided the right platforms for us to pursue the current study. Our aim is to find the incidence of the number of roots in maxillary second molars.

\section{MATERIAL AND METHODS}

In the present study, a total of 50 CBCT scan reports were collected from the Radiology department, Saveetha Dental College, Chennai, for evaluation. The CBCT scans were analysed for the number of roots and number of root canals present in maxillary second molars. Dependent variables were the maxillary second molars, number of root canals, number of roots. Independent variables were the name, age, gender. The data collected were cross verified by another examiner. The collected results were entered in Microsoft excel. Data analysis was done using SPSS software 20.0. Statistics used for analysis was Descriptive statistics and comparison of variables were done using chi square test where $\mathrm{p}<0.05$, statistically significant.

\section{RESULTS AND DISCUSSION}

The study results that the incidence of three roots are $83 \%$, two roots are $10 \%$, one root is $5 \%$ and four roots are $2 \%$ (Figure 1). The incidence of three root canals are $86 \%$, four root canals are $11 \%$ and two root canals are $3 \%$ ( Figure 3). According to figure 2 chi-square tests $p$ value $=0.9>0.05$ statistically not significant. And according to figure 4 chi-square tests $p$ value $=0.7>$ 0.05 statistically not significant. The study revealed the occurrence of three roots with three root canals (76\%) were higher than three roots with four root canals (7\%). The incidence of fused roots, that is, the presence of two roots with three root canals (7\%) were more prevalent than one root with three canals (3\%). There were also incidence of four roots with four root canals (2\%). And according to chi-square tests $\mathrm{p}$ value $=0.0<0.05$ statistically significant. (Figure 5).

Figure 1: This graph represents the number of roots present in the maxillary second molars. $\mathrm{X}$ - axis depicts the number of roots and $\mathrm{Y}$-axis depicts the number of teeth. The results from this graph show that maxillary second molars (17 and 27) mostly have three roots (green-83\%) but sometimes they may also contain two roots (red-10\%) or a single root (blue-5\%) and in very rare conditions it may also contain four roots (orange-2\%).

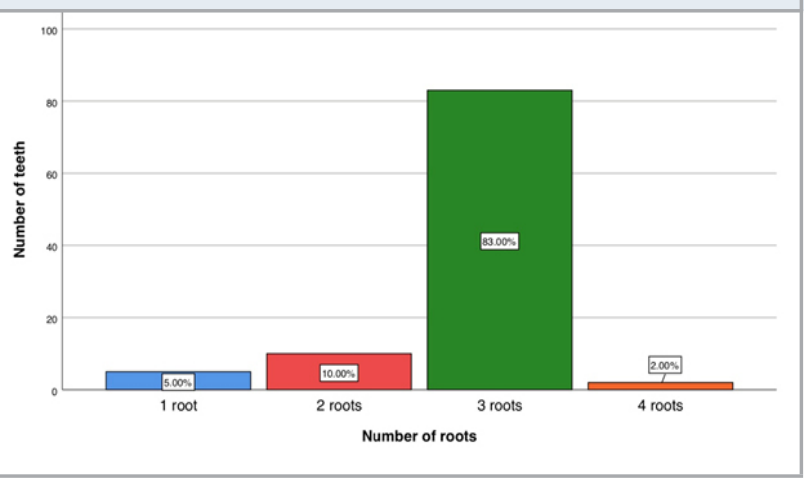

Most studies on anatomical variations of maxillary molars appear to deal with maxillary first molars, as anatomical variations in second molars are not so common. Only a few cases of maxillary second molars have been reported with variations in the number of roots and root canals such as two $\mathrm{MB}$ roots, three $\mathrm{MB}$ canals, two palatal roots with two or three root canals, and a second distobuccal (DB) canal. (Deveaux, 1999) (Libfeld and Rotstein, 1989) (Fahid and Taintor, 1988) (Kottoor et al., 2010) 
Figure 2: This graph shows the association between the tooth number and the number of roots present. $\mathrm{X}$-axis depicts the tooth number and Y-axis depicts the number of the teeth. The results from this graph show that there is no significant difference between the right (17) and left (27) maxillary second molars in the number of roots. Chisquare tests were done and the association was found to be statistically insignificant ; $p$ value $=0.9(>0.05)$ hence not statistically not significant.

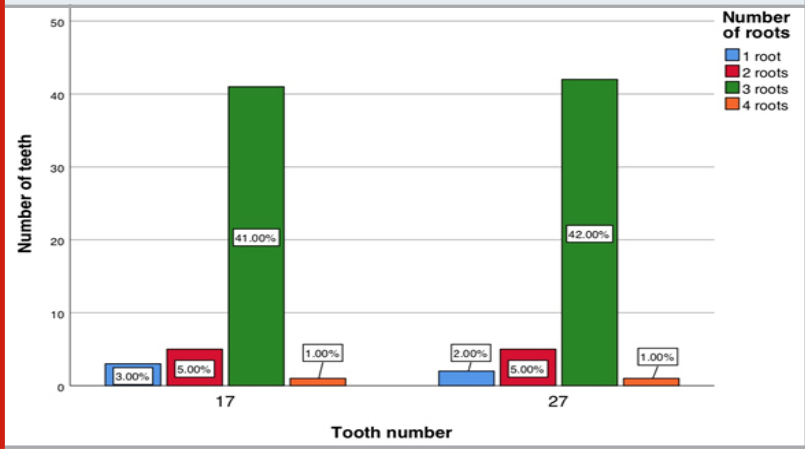

Figure 3: This graph represents the number of root canals present in the maxillary second molars. X- axis depicts the number of root canals and Y-axis depicts the number of teeth. The results from the graph shows that the maxillary second molars (17 and 27) mostly have three root canals (blue-86\%) but sometimes they may also contain four root canals (pink-11\%) and in rare conditions it may also contain two root canals (Yellow-3\%). The incidence of three root canals $(86 \%)$ are more prevalent than other numbers of root canals.

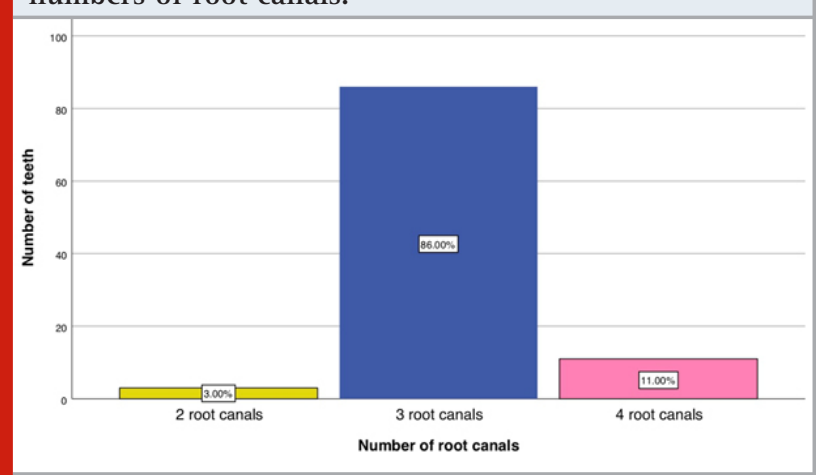

Peikoff et al. (Peikoff, Christie and Fogel, 1996) stated that $3.1 \%$ of maxillary second molars had one root and one canal. The incidence of fused roots in maxillary second molars was investigated by Kim et al (Kim, Lee and Woo, 2012) in a Korean population using CBCT and was found to be $10.7 \%$. Similarly, Zhang et al. (Zhang et al., 2011) in a Chinese population using CBCT found the incidence of a single root in maxillary second molars to be $10 \%$. When only one root is present, the root canal system may commonly present with a single broad root canal or two canals that may or may not join or a C-shaped canal.

Carlsen et al (Carlsen et al., 1992) investigated 104 singlerooted maxillary second molars from a Scandinavian population by sectioning technique and found that 25.96\% of single-rooted maxillary second molars had a single canal at the mid-root level. Hartwell and Bellizzi (Hartwell and Bellizzi, 1982) in their study of 176 teeth concluded that the occurrence of maxillary second molars with a single root and a single canal was 0.6\%. Libfeld and Rotstein (Libfeld and Rotstein, 1989) in an Israel population reported that this configuration was present in $0.5 \%$ of teeth.According to Wang et al., (Wang, Hui and Huang, 2011) the occurrence of maxillary second molars with single root and a single canal is very rare. Christie et al. (Christie, Peikoff and Fogel, 1991) have reported four-rooted maxillary second molar abnormalities, that included two palatal roots.

Figure 4: This graph shows the correlation between the tooth number and the number of roots canals present. $\mathrm{X}$-axis depicts the tooth number and $\mathrm{Y}$-axis depicts the number of the teeth. The results from this graph shows there is no significant difference between the right (17) and left (27) maxillary second molars in the number of roots canals. Chi-square tests were done and the association was found to be statistically insignificant ; $p$ value $=0.7$ (>0.05) hence statistically not significant.

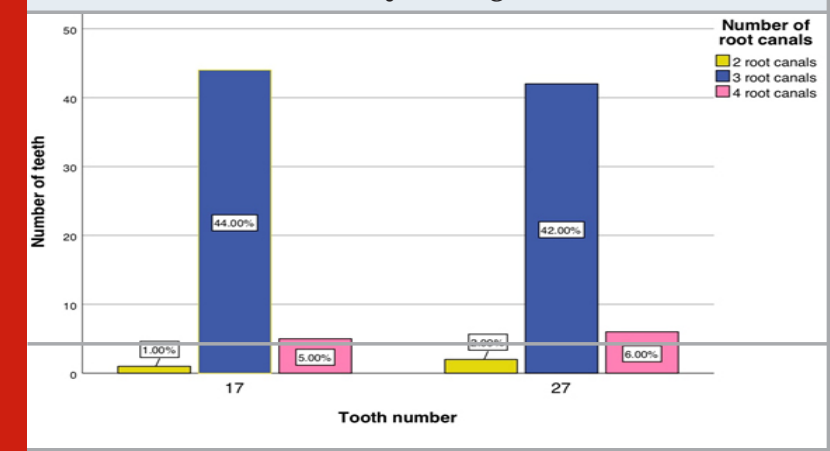

Figure 5: This graph shows the correlation between the number of roots and the number of roots canals present. $\mathrm{X}$-axis depicts the number of roots and $\mathrm{Y}$-axis depicts the number of the teeth. The results from this graph shows that three roots with three canals (blue) was mostly commonly seen (76\%) followed by three roots and four canals (pink-7\%) and two roots and three canals (blue 7\%). Chi-square tests were done and the association was found to be statistically significant ; $p$ value $=0.00(<0.05)$ hence statistically significant.

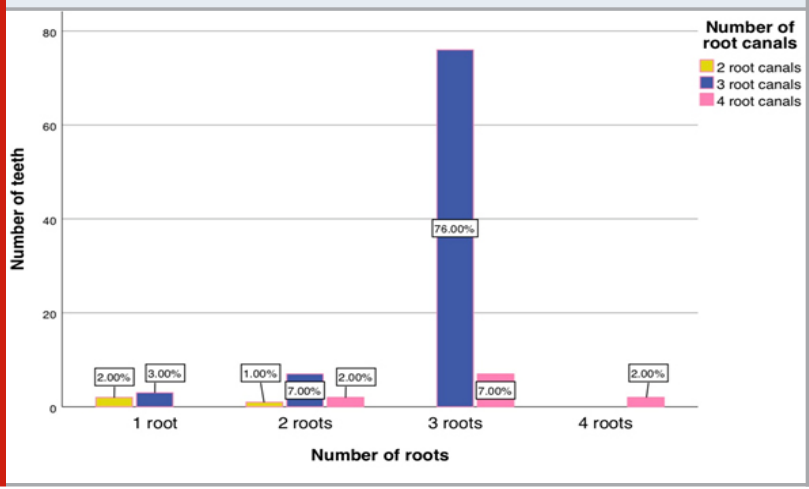




\section{CONCLUSION}

This study revealed that occurrence of the "standard" configuration in maxillary second molars, i.e. three roots with three canals $(76 \%)$ or four canals( $7 \%$ ) was most frequent. Although the occurrence of maxillary second molar with two roots or one root isn't high, diagnosing these unusual cases at its early treatment stage is of significance for the success of endodontic treatment. CBCT must be utilized in these cases when conventional radiographic examination isn't conclusive in identifying the aberrations within the canal anatomy so as to stop excessive dentin removal in search of other canals.

\section{ACKNOWLEDGEMENTS}

I sincerely thank my guide, Department of Conservative Dentistry and Endodontics, radiology department saveetha dental college and hospitals, Saveetha institute Medical and Technical Sciences, Saveetha University for helping me complete the research work.

Conflict of Interest: The authors declare that there were no conflicts of interest in the present study.

\section{REFERENCES}

Azeem, R. A. and Sureshbabu, N. M. (2018) 'Clinical performance of direct versus indirect composite restorations in posterior teeth: A systematic review', Journal of conservative dentistry: JCD, 21(1), pp. 2-9. Cantatore, G., Berutti, E. and Castellucci, A. (2006) 'Missed anatomy: frequency and clinical impact', Endodontic Topics. John Wiley \& Sons, Ltd, 15(1), pp. 3-31.

Carlsen, 0. et al. (1992) 'Root canals in one-rooted maxillary second molars', Scandinavian journal of dental research, 100(5), pp. 249-256.

Christie, W. H., Peikoff, M. D. and Fogel, H. M. (1991) 'Maxillary molars with two palatal roots: a retrospective clinical study', Journal of endodontia, 17(2), pp. 80-84.

Deveaux, E. (1999) 'Maxillary second molar with two palatal roots', Journal of endodontia, 25(8), pp. 571-573.

Fahid, A. and Taintor, J. F. (1988) 'Maxillary second molar with three buccal roots', Journal of endodontia, 14(4), pp. 181-183.

Govindaraju, L., Neelakantan, P. and Gutmann, J. L. (2017) 'Effect of root canal irrigating solutions on the compressive strength of tricalcium silicate cements', Clinical oral investigations, 21(2), pp. 567-571.

Hartwell, G. and Bellizzi, R. (1982) 'Clinical investigation of in vivo endodontically treated mandibular and maxillary molars', Journal of endodontia, 8(12), pp. 555-557.

Janani, K. and Sandhya, R. (2019) 'A survey on skills for cone beam computed tomography interpretation among endodontists for endodontic treatment procedure', Indian journal of dental research: official publication of Indian Society for Dental Research, 30(6), pp. 834-838.

Jenarthanan, S. and Subbarao, C. (2018) 'Comparative evaluation of the efficacy of diclofenac sodium administered using different delivery routes in the management of endodontic pain: A randomized controlled clinical trial', Journal of conservative dentistry: JCD, 21(3), pp. 297-301.

Khandelwal, A. and Palanivelu, A. (2019) 'Correlation Between Dental Caries And Salivary Albumin In Adult Population In Chennai: An In Vivo Study', Brazilian Dental Science, 22(2), pp. 228-233.

Kim, Y., Lee, S.-J. and Woo, J. (2012) 'Morphology of Maxillary First and Second Molars Analyzed by ConeBeam Computed Tomography in a Korean Population: Variations in the Number of Roots and Canals and the Incidence of Fusion', Journal of Endodontics, pp. 1063-1068. doi: 10.1016/j.joen.2012.04.025.

Kottoor, J. et al. (2010) 'Maxillary second molar with 5 roots and 5 canals evaluated using cone beam computerized tomography: a case report', Oral surgery, oral medicine, oral pathology, oral radiology, and endodontics, 109(2), pp. e162-5.

Libfeld, H. and Rotstein, I. (1989) 'Incidence of fourrooted maxillary second molars: literature review and radiographic survey of 1,200 teeth', Journal of endodontia, 15(3), pp. 129-131.

Malli Sureshbabu, N. et al. (2019) 'Concentrated Growth Factors as an Ingenious Biomaterial in Regeneration of Bony Defects after Periapical Surgery: A Report of Two Cases', Case reports in dentistry, 2019, p. 7046203.

Manohar, M. P. and Sharma, S. (2018) 'A survey of the knowledge, attitude, and awareness about the principal choice of intracanal medicaments among the general dental practitioners and nonendodontic specialists', Indian journal of dental research: official publication of Indian Society for Dental Research, 29(6), pp. 716-720.

Nandakumar, M. and Nasim, I. (2018) 'Comparative evaluation of grape seed and cranberry extracts in preventing enamel erosion: An optical emission spectrometric analysis', Journal of conservative dentistry: JCD, 21(5), pp. 516-520.

Peikoff, M. D., Christie, W. H. and Fogel, H. M. (1996) 'The maxillary second molar: variations in the number of roots and canals', International endodontic journal, 29(6), pp. 365-369.

Poorni, S., Srinivasan, M. R. and Nivedhitha, M. S. (2019) 'Probiotic strains in caries prevention: A systematic review', Journal of conservative dentistry: JCD, 22(2), pp. 123-128.

Rajakeerthi, R. and Ms, N. (2019) 'Natural Product as the Storage medium for an avulsed tooth - A Systematic Review', Cumhuriyet Dental Journal, 22(2), pp. 249256.

Rajendran, R. et al. (2019) 'Comparative Evaluation of Remineralizing Potential of a Paste Containing 
Bioactive Glass and a Topical Cream Containing Casein Phosphopeptide-Amorphous Calcium Phosphate: An in Vitro Study', Pesquisa brasileira em odontopediatria e clinica integrada, 19(1), pp. 1-10.

Ramarao, S. and Sathyanarayanan, U. (2019) 'CRA Grid - A preliminary development and calibration of a paper-based objectivization of caries risk assessment in undergraduate dental education', Journal of conservative dentistry: JCD, 22(2), pp. 185-190.

Sha, X., Sun, H. and Chen, J. (2018) 'Maxillary second molar with four roots and five canals', Journal of dental sciences, 13(2), pp. 167-171.

Siddique, R. et al. (2019) 'Qualitative and quantitative analysis of precipitate formation following interaction of chlorhexidine with sodium hypochlorite, neem, and tulsi', Journal of conservative dentistry: JCD, 22(1), pp. 40-47.

Siddique, R. and Nivedhitha, M. S. (2019) 'Effectiveness of rotary and reciprocating systems on microbial reduction: A systematic review', Journal of conservative dentistry: JCD, 22(2), pp. 114-122.

Siddique, R., Nivedhitha, M. S. and Jacob, B. (2019) 'Quantitative analysis for detection of toxic elements in various irrigants, their combination (precipitate), and para-chloroaniline: An inductively coupled plasma mass spectrometry study', Journal of conservative dentistry: JCD, 22(4), pp. 344-350.

Teja, K. V., Ramesh, S. and Priya, V. (2018) 'Regulation of matrix metalloproteinase-3 gene expression in inflammation: A molecular study', Journal of conservative dentistry: JCD, 21(6), pp. 592-596.

Wang, Y., Hui, X. and Huang, D. M. (2011) 'Maxillary second molar with curved single root and single canal: a case report', Hua xi kou qiang yi xue za zhi= Huaxi. europepmc.org. Available at: https://europepmc.org/ article/med/21427914.

Zhang, R. et al. (2011) 'Use of CBCT to identify the morphology of maxillary permanent molar teeth in a Chinese subpopulation', International endodontic journal, 44(2), pp. 162-169. 